Marco Brusotti

Wittgenstein, Frazer und die „ethnologische Betrachtungsweise“ 


\section{Über Wittgenstein}

Herausgegeben im Auftrag der Internationalen Ludwig Wittgenstein Gesellschaft e.V. von James Conant, Wolfgang Kienzler, Stefan Majetschak, Volker Munz, Josef G.F. Rothhaupt, David Stern und Wilhelm Vossenkuhl

\section{Band 2}




\section{Marco Brusotti}

Wittgenstein, Frazer

und die „ethnologische Betrachtungsweise"

DE GRUYTER 
ISBN 978-3-11-037046-1

e-ISBN 978-3-11-036611-2

\section{Library of Congress Cataloging-in-Publication Data}

A CIP catalog record for this book has been applied for at the Library of Congress.

\section{Bibliografische Information der Deutschen Nationalbibliothek}

Die Deutsche Nationalbibliothek verzeichnet diese Publikation in der Deutschen Nationalbibliografie; detaillierte bibliografische Daten sind im Internet über http://dnb.de abrufbar.

(C) 2014 Walter de Gruyter GmbH, Berlin/Boston Druck und Bindung: Hubert \& $\mathrm{Co} . \mathrm{GmbH} \& \mathrm{Co}$. KG, Göttingen @ Gedruckt auf säurefreiem Papier Printed in Germany 